\title{
ANALISIS TARBIYAH TENTANG BERKAH RAMADHAN DAN 'IDUL FITRI
}

\section{Oleh :}

\author{
Nurfin Sihotang ${ }^{1}$
}

\begin{abstract}
This paper exsplain about the Ramadhans month as the famos time in the life of Moslem, so many worship their do in the month of Ramdhan as fasting in the noon, pray traweh in the night and reading the holy Qur'an and another worship. The writhing of this paper tray to analysis of the many worship in Ramadhan to fine the marks in moslem life from that analysis the moslems gets goods spritwal, intlektwal and emotional in them life
\end{abstract}

Keywords: tarbiyah; analysis; blessing.

\section{PENDAHULUAN}

Ramadhan dikenal dengan Saiydusy Syuhur, Syahrul Mubarak, Syahrul Qur'an, Syahrul Maghfirah,Syahrush Shiyam, Syahrul Ibadah . pernyatan ini mengisyaratkan perlunya mengkaji dan menggali Ramadhan guna mengetahui, memahami dan mengusai pesan inti yang ada didalamnya dalam rangkan menambal Ilmu, Amal dan Iman. Pasinya bahwa setiap sisi sebutan tentang Ramadhan memiliki keberkahan dan menjadi pertanyaan adalah bagaimana menggapai berkah Ramadhan tersebut sehingga menjadi instrumen membina pribadi mukmin yang ideal, inilah yang akan dibahas dalam uraian berikut ini. Diharapkan dengan pendekatan analisis tarbiyah tentang keberkana Ramadha tesebut dalam tulisan ini akan menghasillan berbagai mamfaat untuk semua pihak dan paling tidak mejadi bahan kajian dalam dalam penyaempurnaan kehidupan spritual, emosional, soasial.

\section{BERKAH RAMADHAN DAN 'IDUL FITHRI}

Berikut ini merupakan penjelasan tentang keberkahan ramadhan dan idhul fitri yang dalam poin-poin berikut:

\section{Berkah Ramadhan}

Berkabih dari bahasa Arab; Baraka- Mubarakun; katsirul Manafi'u'dDunyawiyah wal-Ukhrawiyah ${ }^{2}$ artinya; banyak kebaikannya, banyak manfaatnya, dunia dan akhirat.

Menurut bahasa Ramadhon ;Minar Romdhi; Syiddatul Har artinya panas yang bersangatan dikatakan Ramadhan karena dia membakar dosa ${ }^{3}$. Ramadhan

\footnotetext{
${ }^{1}$ Penulis adalah Dosen Prodi Bahasa Arab IAIN Padangsidimpuan

2 Muhammad Ali Ash Shabuni, Shafwatut Tafasir (Beirut; Darul Kutubul Ilmiyah 1999) hlm.334.

${ }^{3}$ M. Ali Shabuni, h. 86
} 
membakar dosa tidaklah dengan kayu bakar tapi dengan amal dan ibadah dengan kerangka amal ibadah sebagaiman berikut;

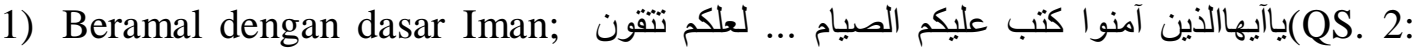

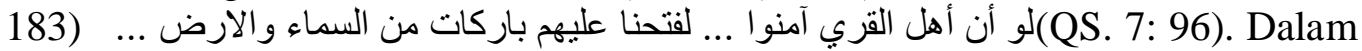

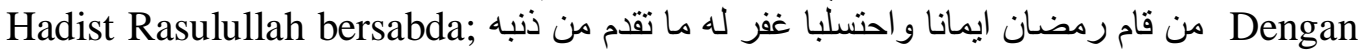
kerangka ini akan menggapai; Taqwa, berkat dari bumi dan langit dan dosa yang diampunkan.

2) Beramal Lillah dengan Usaha; Istiqomah, meyempurnakan, memperbaiki, meningkatkan: وأن لبس للانسان الا ماسعى وأن سعيه سوف يرى (QS.53: 39-40) . Dengan Kerangka ini akan menggapai hasil di dunia dan akhirat.

3) Beramal dengan dasar Taqwa4: ومن بتق الله يجعل لله مخرج ويرزقه من حيث لا يحتسب

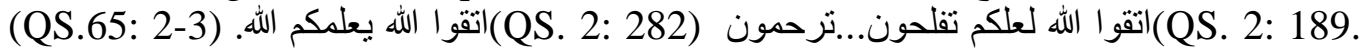
6:155). Dengan kerangka ini akan menggapai solusi, rezki yang tak terduga, diajari Allah, sukses dan disayang Allah.

4) Beramal dengan Tawakkal: ومن يتوكل على الله فهو حسبه ان الله بالغ أمره(QS. 65:3). Dengan kerangka ini akan dijaga Allah dan harapan terwujud.

5) Ber amal Shaleh: من عمل صالحا من ذكر أو أنثى وهو مؤمن فلنحينه حياة طيبة.

6) ومن عمل صالحا من ذكر و أنثى و هو مؤمن فأولئك يدخلون الجنة (QS.40: 40). Dengan kerangka ini kehidupan akan baik didunia dan diakhirat.

7) Beramal sebagai bukti Syukur : لئن شكرتم لأزيدن كم(QS. 14:7). Dengan kerangka ini Allah akan menambah nikmatnya.

8) Beramal sebagai Do’a : أجيب دعوة الداع اذا دعان(QS. 2: 186).

9) Dan dalam waktu yang sama sadar sepenuhnya firman Allah (QS.99: 7-8)

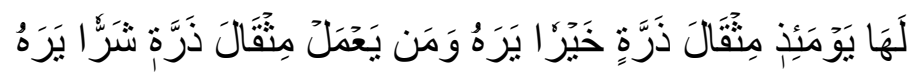

Barangsiapa yang mengerjakan kebaikan seberat dzarrahpun, niscaya Dia akan melihat (balasan)nya dan Barangsiapa yang mengerjakan kejahatan sebesar dzarrahpun, Niscaya Dia akan melihat (balasan)nya pula.

Adapun bentuk bentuk amal pada bulan Ramadhan diantarnya adalah;

Pertama, bepuasa pada siang hari mulai terbit fajar sampai tenggelam matahari Qiyamul lail setiap malam Ramadhan dengan tarawih dan witir, Karena Sabda Rasukullah " Man qoma Ramadhan Imanan wahtisaban ghufira lahu ma taqoddama mi dzanbih" Kedua, Membaca, bertadarus dan metadabbur al-Qur'an Qiyamulailatul Qadr/Lailatul Mubarak karena malamini lebih baik dari seribu bulan " Khairun min alfi syahri" Ketiga, Bersedekah " Afdholush Shadaqah shdaqatu fi Ramadhan" Keempat, Menunaikan Zakat Fitrah atau Zakat Mal. "Khudz min amwalihim Shadaqatan tuthahhirumu wa tuzkkihim biha...'(QS.9:103). Kelima, I'tikaf karena Rasulullah I'tikaf pada 10 terakhir Ramadhan Do'a dan seterusnya Insya Allah dengan kerangka tersebut amal ibadah Rhamadhan menjadi berkah yaitu harapan akan menjadi kenyataan; ...La'akum tattaquun. ...La'alakum tasykuruun...La'alakum yarsyuduun. (QS. 2: 183, 184, 185)

\footnotetext{
التقوى : الخوف من الجليل ـ و العمل بالتنزيل ـ و القناءة من القليل ـ و الاستعداد بالرحيل4
} 


\section{Berkah 'Idul fithri}

Kata 'Id berakar dari; 'Awuada; berarti membiasakan, 'Ayada; berari merayakan hari raya, 'Aawada; berarti kembali pada keadaan semula. ${ }^{5}$ Dalam Kamus bahasa Indonsia Kembali berarti Balik ketempat semula atau kekeadaan semula $^{6}$ Fitrah; adalah sifat pembawaan yang ada sejak lahir, ${ }^{7}$ Allah berfirman (QS.30: 30)

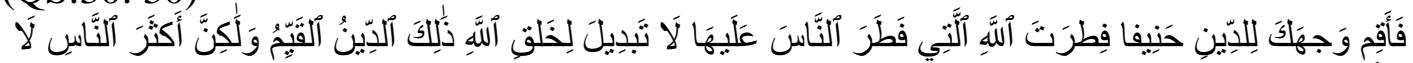

Artinya:

Maka hadapkanlah wajahmu dengan lurus kepada agama Allah; (tetaplah atas) fitrah Allah yang telah menciptakan manusia menurut fitrah itu.Tidak ada peubahan pada fitrah Allah. (Itulah) agama yang lurus; tetapi kebanyakan manusia tidak mengetahui

Menurut al-Ashfahani Fithrah adalah; "Ijadusy Syai wa ibadauhu". 8 sesuatu yang diciptakan dan diadakan dan fitrah ini ada mulai sebelum alam zdur; Fithrak "Kepemimpinan." "Inni ja'ilin fil Ardhi khalifah",(QS.2:30) dan "Fithrah mengesakan Allah dalam beribadah; "Wama kholaqtul Jinna wal-Ins illa liya'buduun:. (QS51; 56) di alam zdur ; Fithrah pengakuan dan pengesaan Allah, "Alastu birabbikum ? qoluu bala syahidna.." (QS.7: 172) di a'alam rahim Fithrah mendengar, melihat, nurani hati dan bersyukur. Wa ja'la lakumus Sam'a wal Abshar Wal Af,idah qolilanma tasykuruun. (QS.32: 9) Inilah fithrah dasar dan bawaan manusi sebelum lahir kedunia fitrak itu (suci bersih tanpa noda dan dosa) di 'alam dunia dunia manusia juga diberi fithrah yaitu Fithrah Isti'mar (QS.11: 61) Fithrah membangun dan menjaga pembangunan serta fithrah pemliharaan, pengembangan dan pembentukan lingkungan dalam hal ini Rasulu bersabda;

(كل مولود يولد على الفطرة ) dan di 'alam akhirat fithrah menjadi saksi bagi dirinya; Balil Insan ala nafsihi bashirah (QS.75: 14)

Jadi dimaksud dengan berkah 'Idul Fithri berarti manusia yang mengamalkan amalan Ramadhan dan Idul Fithri berari kembali keposisi semula tanpa noda dan dosa "Kembali seperti waktu dilahirkan ibuya dan inilah hakikat berkah Ramadhan dan 'Idul Fiithri.

\section{KONSEPSI MANUSIA}

Berikut konsep manusia menurut Islam

\section{Proses Penciptaan Manusia}

Manusia adalah ciptaan Allah sesuai dengan firmaNya. (QS. 32: 7-9)

5 . Ahmad Warson, Kamus Arab Indonesia, (Yokyakarta: Pondok Pesantren al-Munawwir, 1984)

${ }^{6}$ Tim Penyusun, Kamus Besar Bahasa Indonesia Edisi Tiga.(Jakarta: Balai Pustaka 200) h. 537

${ }^{7}$ Ahmad Warson, h. 1142

8 al-Aahfahani, Ma'ani Muradati al-Fazhil-Qur'an. Beirut Darus Syamiyah 1992.h.640 


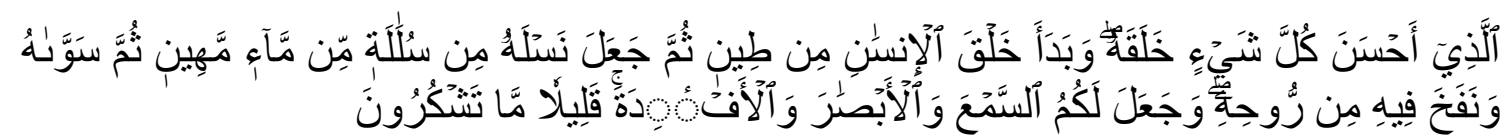

Yang membuat segala sesuatu yang Dia ciptakan sebaik-baiknya dan yang memulai penciptaan manusia dari tanah. Kemudian Dia menjadikan keturunannya dari saripati air yang hina. Kemudian Dia menyempurnakan dan meniupkan ke dalamnya roh (ciptaan)-Nya dan Dia menjadikan bagi kamu pendengaran, penglihatan dan hati; (tetapi) kamu sedikit sekali bersyukur.

Sesungguhnya banyak ayat dalam al-Qu'an yang menjelaskan penciptaan manusia tapi ayat ini dianggap dapat mewakili karena telah menjelaskan proses penciptaan manusia yang diawali dari tanah yaitu Adam AS. Dan keturunannya senyawa ovum dan sperma (menjadi jasad) ditambah "Ruh" setelah itu diciptakan as-Sam'a, wal-Abshar, walAf,idah. Ini adalah bagian dari fithrah untuk bersyukur tapi kenyataan kenyataan menunjukkan banyak manusia yang tidak bersyukur.

\section{Tujuan penciptaan manusia adalah;}

a. Khalifah, pemimpin: انى جاعل فى الأرض خليفة(QS. 2:30)ungkapan "Pemimpin" dalam al-Qur'an disebut dengan kata yang berbeda;

1) “Imam”.انى جاعلاك للناس اماما. (QS.2: 124)

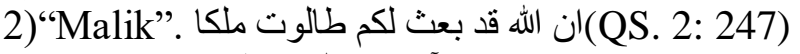

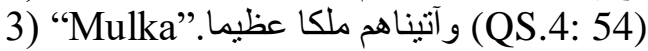

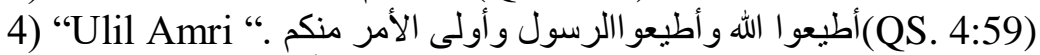

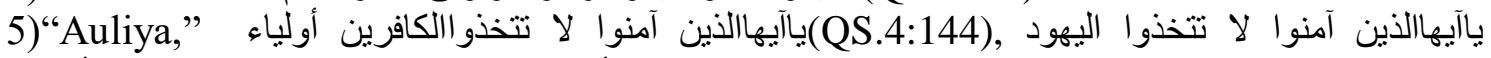

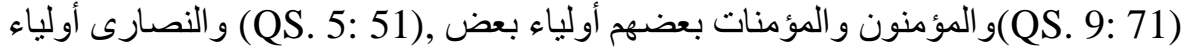

6). “Qawaam”. الرجال قو امون على النساء (QS. 4: 34)

b. Beribadah mengesakan Allah; وما خلقت الجن و الانس الا ليعبدون(QS.51:56)

c. Memakmurkan bumi ( membangun, menjaga pembangunan dan ligkungan ) هو أنشاكم من الأض واستعمركم فيها (QS. 11:61)

Artinya; Dia telah menciptakan kamu dari bumi (tanah) dan menjadikan kamu pemakmurnya $^{9}$

" (QS. 2: 201)

d. Bahagia di Dunia dan Akhirat; ربنا آتنا فى الدنيا حسنة وفى الآخرة حسنة وقنا عذاب النار "

Dalam pendidikan Islam atau tarbiyah Islamiyah tujuan penciptaan manusia equivalen dengan tujuan penciptaan munusia dan pendidikan tersebut meliputi pendidikan rukhiyah fitriyah dan jasmaniyah dan ini dapat dilakukan dengan berbagai bentuk termasuk dengan melakukan berbagai amal pada bulan Ramadhan dan 'Idul Fithri

\section{Fitrah Manusia}

${ }^{9}$ Maksudnya: manusia dijadikan penghuni dunia untuk menguasai dan memakmurkan dunia. 
Fithrah adalah sesuatu yang ditetapkan Allah dalam diri dan luar diri manusia mulai sebelum penciptaan, di 'alam zdur/rahim, 'alam dunia dan 'alam akhirat dalam hal ini Allah berfirman. (QS.30.30)

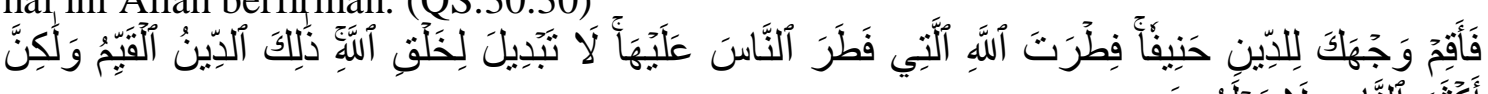

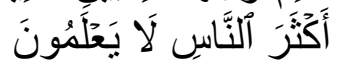

Maka hadapkanlah wajahmu dengan Lurus kepada agama Allah; (tetaplah atas) fitrah Allah yang telah menciptakan manusia menurut fitrah itu. tidak ada peubahan pada fitrah Allah. (Itulah) agama yang lurus; tetapi kebanyakan manusia tidak mengetahui. 10

Dengan demikian jika merujuk kepada al-Qur'an fitrah dapat diklasifikasikan menjadi lima pase yaitu;

1. Pase Sebelum Penciptaan Fithrah Kepemimpinan, (QS.2;30)

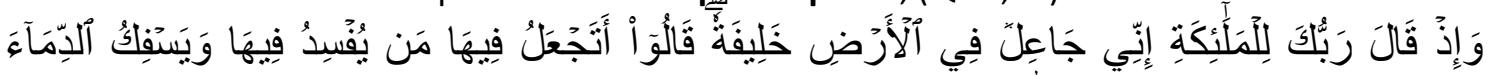

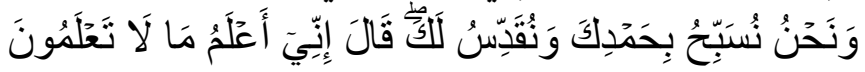

Ingatlah ketika Tuhanmu berfirman kepada Para Malaikat: "Sesungguhnya aku hendak menjadikan seorang khalifah di muka bumi." mereka berkata: "Mengapa Engkau hendak menjadikan (khalifah) di bumi itu orang yang akan membuat kerusakan padanya dan menumpahkan darah, Padahal Kami Senantiasa bertasbih dengan memuji Engkau dan mensucikan Engkau?" Tuhan berfirman: "Sesungguhnya aku mengetahui apa yang tidak kamu ketahui."

dan Fithrah Beribadah (QS.51: 56)

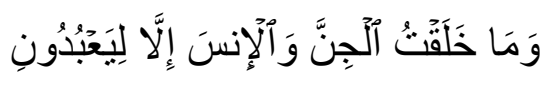

Artinya;56. dan aku tidak menciptakan jin dan manusia melainkan supaya mereka mengabdi kepada-Ku.

Kedua fithrah ini telah ditetapkan oleh Allah sebelum manusia itu diciptakan agar manusia tetap dalam fithrahnya

2. Pase 'Alam Zhur Fithrah pengakuan Tauhidullah, Allah berfirman. (QS. 7: 127)

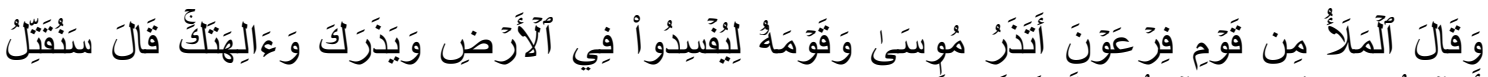

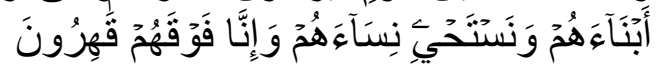

Artinya; Dan (ingatlah), ketika Tuhanmu mengeluarkan keturunan anak-anak Adam dari sulbi mereka dan Allah mengambil kesaksian terhadap jiwa mereka (seraya berfirman): "Bukankah aku ini Tuhanmu?" mereka menjawab: "Betul (Engkau Tuban kami), Kami menjadi saksi". (kami lakukan yang demikian itu) agar di hari kiamat kamu tidak mengatakan: "Sesungguhnya Kami (Bani Adam) adalah orang-orang yang lengah terhadap ini (keesaan Tuhan)"

\footnotetext{
${ }^{10}$ Fitrah Allah: Maksudnya ciptaan Allah. manusia diciptakan Allah mempunyai naluri beragama Yaitu agama tauhid. kalau ada manusia tidak beragama tauhid, Maka hal itu tidaklah wajar. mereka tidak beragama tauhid itu hanyalah lantara pengaruh lingkungan.
} 
Selain dari fithrah kesadaran bertuhan tersebut manusia juga dibekali berbagai fitrah lainnya berikutnya.

3. Pase 'Alam Rahim; Fithrah, s-Sam'a, wal-Abshar, wal-Afidah termasuk bersyukur(QS. 32: 9)

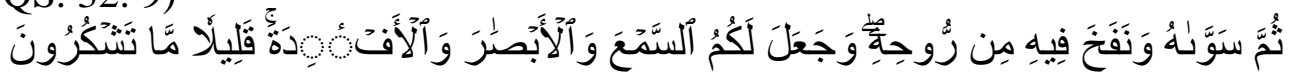

Kemudian Dia menyempurnakan dan meniupkan ke dalamnya roh (ciptaan)-Nya dan Dia menjadikan bagi kamu pendengaran, penglihatan dan hati; (tetapi) kamu sedikit

sekali bersyukur.

4. Pase 'Alam Dunia Fithrah Isti'marah (membangun/menjaga pembangunan dan lingkungan, (QS.11.61)

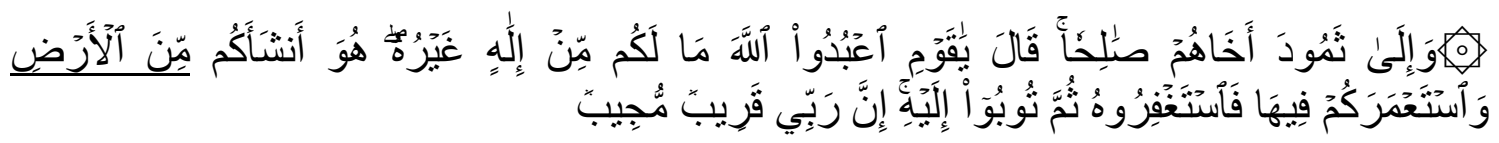

Dari bumi (tanah) dan menjadikan kamu pemakmurnya. ${ }^{11}$

Fitrah Isti'mar adalah menjalankan fungsi sebagai "Khalifah". Pemimpin dan "Abid", beribadah mengesakan Allah dan Isti'mar". membangun dan memelihara pembangunandipermukaan dunia ini termasuk fithrah membentuk lingkungan, dalam hal ini, Rasulullah bersabda;

$$
\text { “كل مولود يولا على الفطرة فآبو اه يو هاودانه أو ينصر انه أو يومجسانه " }
$$

Artinya; "Setiap anak yang dilahirkan berada dalam keadaan fithrah maka bapaknyalah (dirumah, masyarakat, sekolah dan pemerintahan) yang membuatnya menjadi Yahudi atau Nashrani atau Majusi."

5. Pase 'Alam Akhirat, Fithrah kejujuran manusi terhadap apa yang dilakukannya selama hidupnya di'alam dunia fitrah ini akan mengungkapkan kebenaran dengan jujur yang dilakukan manusia selama hidup Allah berfirman;

$$
\text { بلِ ألإنسنْنُ عَلَى نَفَسِيَ بَصِيرَة }
$$

Artinya: Bahkan manusia itu menjadi saksi atas dirinya sendiri (QS.75:14)

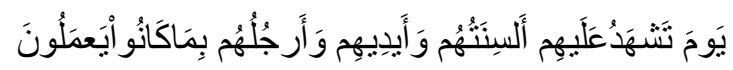
Artinya; " Pada hari (ketika), lidah, tangan dan kaki mereka menjadi saksi atas mereka terhadap apa yang dahulu merekakerjakan (QS. 24:24)

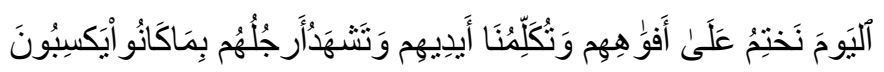

Pada hari ini Kami tutup mulut mereka; dan berkatalah kepada Kami tangan mereka dan memberi kesaksianlah kaki mereka terhadap apa yang dahulu mereka usahakan.

\footnotetext{
${ }^{11}$ Maksudnya: manusia dijadikan penghuni dunia untuk menguasai dan memakmurkan dunia.
} 


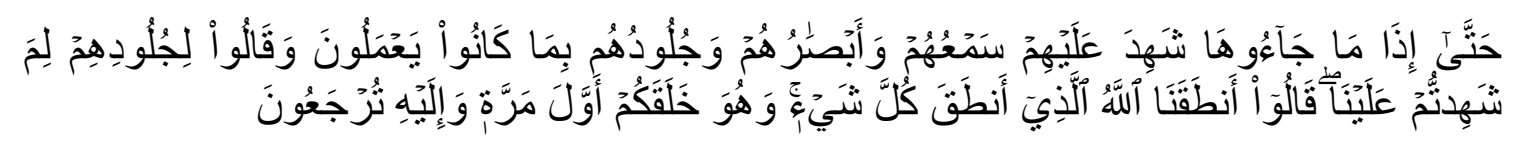

Sehingga apabila mereka sampai ke neraka, pendengaran, penglihatan dan kulit mereka menjadi saksi terhadap mereka tentang apa yang telah mereka kerjakan.dan mereka berkata kepada kulit mereka: "Mengapa kamu menjadi saksi terhadapkami?" kulit mereka menjawab: "Allah yang menjadikan segala sesuatu pandai berkata telah menjadikan Kami pandai (pula) berkata, dan Dia-lah yang menciptakan kamu pada kali pertama dan hanya kepada-Nya lah kamu dikembalikan".(.(Fushshilat:20-21)

Kelima pase fitrah ini; mulai sebelum 'alam zhur, 'alam zhur, 'alam rahim dan'alam dunia serta akhirat adalah satu kesatuan dalam rangka menjaga eksisitentensi dan konsistensi manusia menjalankan fungsi dan tujuan penciptaan yaitu menjalankan aktivitasa hidup dan kehidupan dengan kepemimpinan bertauhid beribadah dan memakmurkan bumi dengan membangun, memelihara dan membentuk lingkungan demi kebahagiaan dunia dan akhirat dan fthrah ini bisa dibedakan tapi tak dapat dipisahkan apalagi diabaikan.

\section{Hakikat Manusia}

Berdasarkan uraian terdahu maka dapat dipahami bahwa hakikat manusia itu kembali kepada asal usulnya dan tujuan penciptaan dan fithrahnya, dari segi asal usul manusia terdiri dari 3 unsur pertaama, jasmaniyah yang bersumber/ berproses dari ovum dan sperma, kedua ruhaniyah bersumber dari Allah dan ketiga unsur nafsaniyah timbul sebagai akibat persesnyawaan jasmaniyah dan ruhaniyah

Ketiga unsur ini adalah satu kesatuan dalam diri yang bernama manusia dan didalamnya ada fithrah sebagai modal dasar dalam pengembangan diri guna mewujudkan tujuan penciptaan dan pengembangan fitrah ini dilakukan melalui pola pendidikan baik pendidikan ruhaniyah dan jasamaniyah pendidikan nafsaniyah adalah perpaduan dari pendidkan jasamani dan rohani

Intinya manusia memliki potensi dasar yaitu; potensi tauhid teologis, al-Imanu biarkanil Iman wal- 'Amalu biarkanil-Islam, wa izharu bi ihsan, ini turunan dari fithraf ; Liya'buduun (QS. 51:56) dan Alastu birabbikum Qoluu bala syahidna (QS. 7: 172) potensi ideologis kepemimpina, individu, keluarga, masyarakat dan negara ini turunan dari fithrah, Inni ja'ilun fil-Ardhi Khalifah (QS. 2: 30) potensi intlijensi intlektual dan emosional ini turunan dari fithrah, as-Sam'a, wal-Abshar, wal-Af,dah dan tasykurun (QS. 32: 9) potensi produktif dan kreatif ini turunan dari fithrah, Wasta'marakum fiha (QS.11. 61) dan Hadist, Yuladu alal fithrah dan potensi jujur ini turunan dari fithrah, Balil-Insanu ala nafsihi bashirah (QS. 75: 14) potensi-potensi inilah yang haruss ditarbiyah dan dikembangkan dalam dunia pendidikan agar manusia sampai dipulau tujuan pendikan dunia dan akhirat

Disisi lain manusia terdiri dari unsur Jasmaniyah, nafsaniyah dan ruhaniyah yang pembinaan dan pendidikan ketiganya harus disinerjikan agar menampilkan kehidupan yang ideal dalam mengisisi kebaikan hidup dan kehidupan dunia dan akhirat

\section{ANALISIS TARBIYAH}


Kata "Tarbiyah" berasal dari 3 akar kata :

1. Roba-Yarbu (رَبَى - يَرْبُبُو), artinya: bertambah dan tumbuh. (QS.Ar Rum : 39).

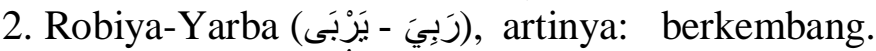

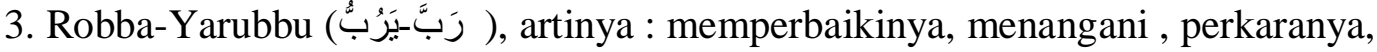
memimpinnya, mengurusnya.

Jadi menurut Ar-Raghib AlAshfahani; الرب فى الأصل : التربية, وهو انثاء الثنئ حالا فحالا

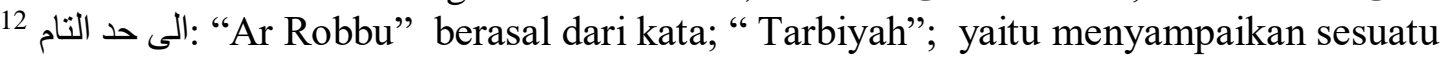
mencapai kesempurnaan dengan cara bertahap.

Dengan demikian dapat dipahami ada 4 unsur tarbiyah :

1. Memelihara fithrah anak yang sedang tumbuh.

2. Mengembangkan minat dan bakatnya

3. Menyalurkan fithrah, minat, dan bakat kepada hal yang positif.

4. Adanya penahapan dalam pencapaiannya.

Mentarbiyah dan memelihara fithrah anak yang sedang tumbuh mulai dari fithrah; kepemimpinan, beribadah, tauhidullah, mendengar, melihat, hati nurani, membangun, memelihara pembangunan dan lingkungan dan berfikir akhirat dan ini rentan dengan godaan oleh karena itu pendidikan dalam hal ini pendidikan Islam mutlak ditampilkan sebagai kewajiban dan solusi diantara tantangan dan godaan itu dalam al-Qur'an disebutkan, (QS. 25: 28: 29)

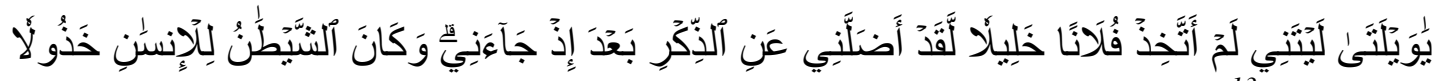

Kecelakaan besarlah bagiku; kiranya aku (dulu) tidak menjadikan sifulan ${ }^{13}$ itu teman akrab(ku). 29. Sesungguhnya Dia telah menyesatkan aku dari Al Quran ketika Al Quran itu telah datang kepadaku. dan adalah syaitanitu tidak mau menolong manusia.

Oleh karena itu pendidikan mutlak menjadi kewajiaban dan kebutuhan guna mewujudkan kesempurnaan manuia dunia dan akhirat pendidikan dimaksud meliputi tarbiyah; Pertama, fitrhrah tauhid teologis, al-Imanu biarkanil Iman wal-'Amalu biarkanil-Islam, wa izharu bi ihsan, ini turunan dari ayat ; Liya'buduun (QS. 51:56) dan Alastu birabbikum Qoluu bala syahidna (QS. 7: 172), Kedua, Fitrhrah ideologis kepemimpina, individu, keluarga, masyarakat dan negara ini turunan dari ayat, Inni ja'ilun fil-Ardhi Khalifah (QS. 2: 30). Ketiga, Fithrah intlijensi intlektual dan emosional ini turunan dari ayat, as-Sam'a, wal-Abshar, wal-Af,dah dan tasykurun (QS. 32: 9). Keempat, Fithrah produktif dan kreatif ini turunan dari ayat, Wasta'marakum fiha (QS.11. 61) dan Hadist, Yuladu alal fithrah. Kelima, Fitrhrah kejujuran ini turunan dari ayat, Balil-Insanu ala nafsihi bashirah (QS. 75: 14)

Fithrah dan potensi inilah yang seharusnya ditarbiyah dan dikembangkan dalam dunia pendidikan agar manusia sampai dipulau tujuan pendikan dunia dan akhirat demi kebahagiaan dunia dan akhirat

\footnotetext{
${ }^{12}$ Al-Ashfahani, Mufrodatu Alfadzu Qur'an,(Beirut : Addaar Assyamiyah 1992)h.336

${ }^{13}$ Yang dimaksud dengan si Fulan, ialah syaitan atau orang yang telah menyesatkannya di dunia.
} 
Dengan melaksanakan Ibadah puasa dan amal Ramadhan lainnya adalah bagian dari tarbiyah ruhaniyah, nafsaniyah dan jasmaniyah karena dengan amal-amal yang ada otomatis fitrah-fithrah yang ada dalam diri manusia akan terjamin dan terpelihara dan dapat mengemban amanah fitrah, sesuai dengan tuntunan syariat.

\section{PENUTUP}

Berkah ramdhan dan 'Idul Fithri akan diperoleh jika dilaksakan dengan kerangka amal sesuai petunjuk syari'ah, baik dari segi syarat, rukun, wajib dan sunatsunatnya. Intinya dengan dengan Ibadah ramadhan dengan berbagai bentuknya akan menjadikan kehidupan rukhaniyah, nafsaniyah dan jasmaniyah menjadi seimbang dan inilah yang disebut sehat jasmani dan ruhani "Shumuu tashihhu". Dan nilai berkah ibadah tersebut adalah bagian dari tarbiyah Fithrah sebelum alam zhur, 'alam zhur/rahim, dunia dan akhirat demi terujudnya hakikat tujuan pendidika bahagia didunia dan akhirat. Wallahu a'lam

\section{DAFTAR}

Al-Qur'an dan Terjemahan

Adnan Syarif, Psikologi Qur'ani, Penj.Muammad al-Mighwar, Bandung: Pustaka 2002, Hidayah

Ahmad Karzon, Anas, Tazkiyatun Nafs, Pentj.Emiel, Jakarta. Akbar Media, 2012.

Ahmad asy-Syarbashi ,Yas'alunaka, Penj. Ahamad Subandi. Jakarta: Lentera, 1997.

As-Fahany, Ar-Ragif al , 1992, Mufradatu al-Fazhul-Qur'an, Beirut: Darul-Qolam.

Ahmad Warson, 1984 Kamus Arab Indonesia, Yokyakarta: Pondok Pesantren alMunawwir.

Muhammad Ali Ash Shabuni, Shafwatut Tafasir, Beirut: Darul Kutubul Ilmiyah , 1999.

Muhammah Husain Abdullah. Mafahimu Islamiyah, Beirut: Darul-Bayariq, 1996.

Sabiq.As-Sayid, Beirut, Fiqhus-Sunnah. Beirut: Darul-Kitabul-`Araby, tt.

Tim Penyusun, Kamus Besar Bahasa Indonesia Edisi Tiga, Jakarta: Balai Pustaka, 2000.

Yusuf Qardhawi, Berinteraksi dengan al-Qur'an, Penj.Abdul Hayye, Jakarta, Gema Insani, 2000.

Wahbah az-Zuhaili, at-Tafsirul-Munir, Beirut: Darul-Fikri, 1991. 